\title{
Manifestaçôes de sofrimento: dilemas e desafios para a vigilância em saúde do trabalhador
}

| ${ }^{1}$ Luís Henrique da Costa Leão, ${ }^{2}$ Luiz Carlos Brant I

Resumo: O artigo aborda as relações complexas e desafiadoras entre as manifestações de sofrimento dos trabalhadores e as práticas da vigilância em saúde. O objetivo deste ensaio é realizar uma análise crítica dos desafios e dilemas relativos à integração da saúde mental no escopo da vigilância em saúde do

1 Saúde Coletiva, Universidade Federal do Mato Grosso. CuiabáMT, Brasil. Endereço eletrônico: luis_leao@hotmail.com

2 Escola de Enfermagem Universidade Federal de Minas Gerais. Belo Horizonte-MG, Brasil. Endereço eletrônico: brant.ufmg@gmail.com trabalhador no Sistema Único de Saúde. Percebemos processos de patologização dos trabalhadores em jogo nas práticas disponíveis na rede de saúde pública. Por isso, com base no pensamento de autores como Agamben, Guattari, Szasz e Rorty, discutem-se dilemas teóricos e práticos, técnicos e éticos do diagnóstico de transtornos mentais relacionados ao trabalho, destacam-se os riscos e perigos da tendência hegemônica centrada na abordagem epidemiológica e psicopatologizante, para lidar com as manifestações de sofrimento dos trabalhadores e, por fim, apontamse alternativas para o desenvolvimento de estratégias institucionais que rompam com os dispositivos de patologização do sofrimento dos trabalhadores.

> Palavras-chave: saúde mental; sofrimento; subjetividade; vigilância; medicalização.

Recebido em: 03/03/2015 Aprovado em: 22/05/2015 
Os problemas sanitários, ocupacionais e ambientais atuais impõem enormes desafios à Vigilância em Saúde do Trabalhador (Visat) no Brasil, dada sua missão de conhecer-intervir nos determinantes e condicionantes da saúde da população trabalhadora.

A efetividade das ações de Visat, entretanto, esbarra em entraves institucionais e políticos, como a insuficiente capacitação de profissionais, pouco apoio financeiro, material e técnico para as atuaçôes in loco, baixo engajamento dos sindicatos e representações de trabalhadores junto aos serviços de saúde e os conflitos com setores empresariais e estatais (LEÃO, 2011). A fragmentação das vigilâncias sanitária, ambiental, epidemiológica para as intervençōes nos processos de produção, somada à ênfase assistencial do Sistema Único de Saúde (SUS), também é um fator que dificulta a implementação das práticas (LEÃO, 2011).

Para superar essas limitações, a Política Nacional de Saúde do Trabalhador e da Trabalhadora (PNSTT) (BRASIL, 2012) objetiva fortalecer a Visat. A meta é que, em 2015, 100\% dos Centros de Referência em Saúde do Trabalhador (Cerest) realizem ações de vigilância.

Várias iniciativas do Ministério da Saúde (MS) vêm sendo traçadas para identificar estratégias de articulação e intervenção em prol das melhorias das condições de trabalho em setores específicos.

Uma das questôes mais urgentes a ser enfrentada pela Visat é o sofrimento dos trabalhadores, pois crescem as demandas para as equipes dos Cerest relativas aos problemas psíquicos, assédios, estresse e outras manifestações. Isso decorre do atual modo de produção-consumo e das características técnicas e sociais da organização pós-fordista, que induzem a novos sofrimentos (RENAULT, 2006; GORZ, 2005; LAZZARATO; NEGRI, 2001).

Apesar da crescente demanda nos serviços de saúde, especialmente na Rede Nacional de Atenção Integral à Saúde do Trabalhador (Renast), existem dificuldades para implementar ações resolutivas e sistemáticas em Visat, pois faltam subsídios para as equipes dos Cerest lidarem com o sofrimento e operacionalizarem fiscalizações nos processos de trabalho com olhar atento à essa dimensão. Frequentemente, essas manifestações são consideradas casos para especialistas e psiquiatras, de forma que muitos Cerest concentram-se em atendimentos clínicos e encaminhamentos para psicólogos, neurologistas e outros profissionais. 
Essa tendência revela o predomínio de modelos clínicos e medicalocêntricos, pautados em especialismos da área $p s i$, que focalizam indivíduos e suas alterações mentais. Como operacionalizar estratégias que superem a hegemonia das práticas clínicas e patologizantes e enfoquem intervenções coletivas na perspectiva da transformação dos processos de trabalho?

Este artigo aborda a temática das práticas de vigilância frente às manifestações de sofrimento dos trabalhadores, considerando a necessidade de desenvolvimento de novas estratégias em Visat. O objetivo é realizar uma análise crítica dos desafios e dilemas relativos à integração da saúde mental na Visat.

Discutimos questôes teóricas e práticas, técnicas e éticas no diagnóstico e notificação de doença mental relacionada ao trabalho na rede de saúde, destacando os riscos desse enfoque, e apontamos alternativas para o desenvolvimento de estratégias de vigilância a partir das manifestações de sofrimento dos trabalhadores.

Tomamos como base as considerações da Sociologia do Diagnóstico, bem como as críticas de Szasz (1977) sobre a medicalização em saúde mental e a noção de produção de subjetividade conforme Guattari (1992). Dialogamos com a crítica epistemológica de Rorty (1994) a fim de discutir o mental da saúde do trabalhador e referenciamo-nos também em Agamben (2007), especialmente sobre a Tanatopolítica, para debater aspectos da Visat em relação à saúde mental. A intenção é oferecer subsídios para a reflexão e ação das equipes de saúde do trabalhador a fim de romper com dispositivos de patologização dos trabalhadores.

\section{A vigilância e sua ênfase nos agravos à saúde mental}

Que dispositivos a vigilância está pondo a funcionar quando utiliza seu modus operandi tradicional para abordar os fenômenos em saúde mental do trabalhador?

Nos procedimentos e recomendaçóes para os serviços de saúde, os fenômenos considerados pertencentes ao escopo da saúde mental dos trabalhadores se restringem basicamente a um conjunto de transtornos mentais.

As diretrizes do Manual de Doenças do Ministério da Saúde (BRASIL, 2001), a lista de doenças relacionadas ao trabalho (BRASIL, 1999) e os mecanismos técnicos de notificação compulsória de agravos (BRASIL, 2011) apresentam os transtornos mentais relacionados ao trabalho e os agentes patógenos e fatores de risco. As doenças elencadas são: lesões orgânicas e cerebrais, transtornos de 
personalidade, demência, delirium, transtorno cognitivo leve, transtorno mental orgânico, episódios depressivos, síndrome da fadiga, alcoolismo crônico, estresse pós-traumático, neurastenia, neuroses profissionais, transtornos do ciclo vigíliasono e a síndrome do esgotamento profissional, entre outros (BRASIL, 2011; $2001 ; 1999)$. Suas causas podem ser metais pesados e produtos perigosos, como brometo de metila, chumbo e agrotóxicos neurotóxicos, capazes de afetar o cérebro (BRASIL, 1999; 2001), e situações da organização do trabalho, como ritmo, intensidade das atividades, fatores mecânicos do posto laboral, conteúdo das tarefas, sistema de turnos, práticas de premiação e incentivos, desacordos entre chefia e colegas, ameaças de desemprego, instabilidade e desemprego.

Essas normativas restringem as manifestações de sofrimento às súmulas nosográficas, conforme o Código Internacional de Doenças (CID), formatando assim uma vigilância de transtornos mentais. Consequentemente, os procedimentos a serem adotados na rede de saúde enfatizam a investigação da presença ou não de transtornos em um indivíduo ou grupo de trabalhadores. Nessa perspectiva, a vigilância pretende detectar trabalhadores transtornados para investigar os casos e estabelecer critérios para a assistência e intervenção nos processos de trabalho.

As ações prioritárias passam a ser identificar, classificar, enquadrar, tratar e recuperar os sujeitos adoecidos. Pois se os "casos" que chegam à rede não são confirmados como transtorno mental por profissional especializado, não se faz a "notificação", nem se organizam equipes para intervir no processo de trabalho. Vigiam-se a doença e os trabalhadores, e não o processo de trabalho.

A vigilância em saúde pública surgiu como um olhar do Estado sobre a população com fins de controle do espaço urbano, efetuado pela polícia médica (SABROZA, s/d). Essa vigilância tradicional é um dispositivo sanitário de controle e disciplina das sociedades modernas, que emergiu para coletar informações sobre doenças e mortes na população e conter endemias e epidemias (DECLICH; CARTER, 1994). Seus métodos e meios de deteç̧ão precoce e controle de doenças foram se alterando ao longo do tempo, acompanhando as tendências do mundo econômico e a ele servindo (SABROZA, s/d).

Monitoramento, controle e registro contínuo de fatos, conhecimentos e doenças são uma tendência da sociedade disciplinar (FOUCAULT, 1987; DELEUZE, 1992) e perpassam diferentes âmbitos do tecido social, incluindo 
o campo da saúde. Por isso, a busca de sinais e signos de transtornos mentais configura uma situação problemática, porque o Estado é chamado a operar dispositivos que possam garantir um "pensar saudável" e, para isso, busca definir e controlar o pensar e sentir insanos.

Se na primeira Revolução Industrial a medicina de fábrica foi convocada para a manutenção da força física, perguntando ao sujeito, como fez Ramazzini, “o que você faz?", na modernidade líquida, a pergunta é: "o que você pensa”? Diferentemente de Taylor, em 1911, que afirmava que o trabalhador não precisava pensar, na contemporaneidade, é a condição que ele pense, crie e tome decisões rápidas, que o definem como produtivo, apto e saudável.

Os dispositivos de disciplina dos horários, movimento dos corpos, coordenação de operações e cerceamento do espaço que vigoraram nas primeiras fases do capitalismo estão em declínio na sociedade de controle (DELEUZE, 1992). Os ganhos de produtividade estão atualmente vinculados à gestão da subjetividade, e são requeridas maiores responsabilidades e maior engajamento do corpo e da alma (RENAULT, 2006), pois é justamente "a alma do operário que deve descer na oficina” (LAZZARATO; NEGRI, 2001, p. 25).

Na sociedade pós-fordista, ocorre uma transformação da relação do sujeito com a produção, que passa a envolver o ciclo reprodução-consumo. A distinção entre tempo/espaço de trabalho e tempo/espaço livre torna-se tênue demais, de forma que o trabalho não se reproduz tanto como forma de exploração, mas de reprodução de subjetividade, pois "[a] 'matéria-prima' do trabalho imaterial é a subjetividade" (LAZZARATO; NEGRI, 2001, p. 46). A subjetividade é forjada pelos variados elementos da sociedade, de maneira que os sujeitos são construídos através de longos e complexos caminhos, engajando, através da família, da escola, sistemas maquínicos, e todas as facetas da subjetividade (cognitiva, afetiva, perceptiva, volitiva, mnêmica) seriam modeladas dessa forma (GUATTARI, 1992).

Se a subjetividade é formada nas malhas da história, podemos afirmar que existe uma subjetividade em produção dentro dos modos capitalistas de organizar os espaços de trabalho e consumo. Nesse sentido, não haveria uma dada essência humana que no processo de trabalho entraria em "desgaste físico e mental", ou mesmo não ocorreria uma "corrosão do caráter" dos trabalhadores. Existiria, sim, a produção de uma subjetividade, pois é exatamente nisso que investe o trabalho contemporâneo à mercê de seus padrões. Assim, os dispositivos da vigilância - 
1276 ênfase no nexo causal, diagnóstico de transtornos, entre outros - podem cooperar nesse processo de (re)produção de subjetividades.

\section{Dilemas do diagnóstico para o nexo causal e notificação}

Conforme os trâmites da vigilância, para que um transtorno seja reconhecido em uma unidade de saúde, para notificação e tratamento, faz-se necessária uma série de entrevistas, exames psicológicos-psiquiátricos e laudos. Em tese, dependese da interpretação de especialistas em Psicologia, Psiquiatria ou grupos de profissionais especializados. Trata-se de açôes clínicas porque requerem exames, avaliaçôes psicológicas e demais meios cabíveis para o diagnóstico diferencial. Essas práticas demandam experiência e formação específica, principalmente nos casos em que, segundo os códigos de doença, a patologia não possui vinculação direta com o trabalho ou lesão orgânica.

Laudos técnicos são então considerados cruciais para doenças tipo II e III, classificadas como tendo possíveis ligações com o trabalho (JARDIM; RAMOS; GLINA, 2010). Duas ações podem contribuir para esse tipo de diagnóstico: inspeções no trabalho e levantamentos epidemiológicos que subsidiam o nexo causal, pois evidenciam a incidência, prevalência e magnitude na categoria profissional enfocada (JARDIM; RAMOS; GLINA, 2010).

Os diagnósticos são práticas da clínica, voltadas para os indivíduos. As inspeçôes e levantamentos epidemiológicos a ela servem e, em última instância, dela dependem. Nesse processo, emergem dilemas éticos, técnicos, culturais e simbólicos.

Até o século XIX, o diagnóstico de mal-estar e doenças estava centrado nas narrativas do paciente, interpretadas, aceitas e valorizadas. Com o tempo, ocorre um silenciamento dos sujeitos, quando o diagnóstico passa a se basear em sinais e signos de uma patologia, detectados por observação clínica, com auxílio de instrumentos tecnológicos e exames químicos, entre outros, fazendo aumentar o poder dos médicos e a especialização do saber (ANSPACH, 2011). Ocorre um deslocamento da narrativa do sujeito sobre sua experiência da doença, sintoma, mal-estar e desconforto em direção à busca de patologias no corpo (ANSPACH, 2011; FOUCAULT, 1998). O sofrimento humano foi sendo paulatinamente interpretado como doença, patologia, transtorno, neurose, depressão. Além da "corporificação", observa-se também a medicalização - e consequente 
individualização, culpabilização e vitimização - de problemas cuja causalidade não estaria no corpo (biológico) ou nas instâncias psíquicas, mas nas relações sociais.

Os diagnósticos e o estabelecimento de nexo causal não são ações isentas de valores morais e ideológicos. Não se trata de atos objetivos pautados em critérios neutros e científicos, pois são práticas sociais carregadas de simbolismos culturalmente determinados. Os sistemas de classificação psiquiátrica são conformados histórica e culturalmente e mediados por convenções e significados sociais. É a junção dos fatores históricos e culturais com biológicos e físicos do ambiente que constitui o material dos distúrbios psiquiátricos (FABREGA, 1996). "A noção de sintoma mental está, desse modo, intrinsecamente ligada ao contexto social e particularmente ético no qual é elaborada, assim como a noção de sintoma físico está ligada a um contexto anatômico e genético" (SZASZ, 1977, p. 21). Consequentemente, não é raro encontrar relatos de trabalhadores adoecidos, por exemplo, por Lesōes por Esforços Repetitivos, que tiveram de lutar para provar seu adoecimento (VERTHEIN; MINAYO-GOMEZ, 2011). De alguma forma, instalam-se práticas concretas baseadas na suspeita de que os pacientes estão utilizando seus sintomas para obter ganhos secundários, um afastamento do trabalho ou benefício financeiro.

Esse procedimento acaba colocando o sujeito trabalhador no papel de "espertalhão" e enganador, negando sua fala e narrativa de sofrimento. $\mathrm{O}$ profissional de saúde assume assim, sob o signo de sua autoridade legalprofissional e simbólica, um papel de agente moral cuja missão é interpretar "mentiras e verdades" deixando em segundo plano a necessária escuta das narrativas de sofrimento. Seria mais exato então falar em diagnósticos morais e nexos morais, baseados nas pressuposições e interações suscitadas na relação face a face entre profissionais e trabalhadores em atendimento. Assim, o diagnóstico dos transtornos mentais pode caracterizar um "diagnóstico moral” baseado em julgamento a partir de critérios e valores culturalmente condicionados, cujo nascimento reporta ao século XIX, na Europa e Estados Unidos, e, no Brasil, às primeiras décadas do século XX.

No âmbito do SUS, uma das principais diretrizes é a notificação compulsória de transtornos mentais e do comportamento relacionados ao trabalho para alimentar o SINAN (Sistema de Informação de Agravos de Notificação). Para que ela seja realizada, é preciso haver um diagnóstico de transtorno mental. 
Existe grande esforço para capacitar a rede de saúde pública nessa direção - aumentar as notificações e construir um banco de dados incluindo esses transtornos. Esse dispositivo de controle transforma em patologia de notificação obrigatória uma ampla gama de sofrimentos dos trabalhadores com o status quo do atual momento da organização do trabalho. Por isso, essa prática precisa ser questionada, porque pode configurar um agenciamento do "Capitalismo Mundial Integrado", na perspectiva de Guattari (2000).

No Capitalismo Mundial Integrado, os sujeitos vivem uma ruptura radical em todas as dimensões da vida, que se concretizam em novas maneiras de viver e de morrer e que exigem novos modos de pensar e de fazer. Os modos de vida humanos, individuais e coletivos, evoluem no sentido de uma progressiva deterioração, que pode ser constatada nas doenças relacionadas ao trabalho, violência urbana, desemprego, estresse, solidão, ociosidade, angústia, depressão ou dependência química, entre outras (GUATTARI, 2000). Afinal, o que se faria e o que se faz com o enorme contingente de "notificados" como adoecidos psíquicos pelo trabalho? Seria uma ingenuidade acreditar que o portador desse diagnóstico, como tal, não ganharia visibilidade no âmbito laboral, apesar de todas as medidas de sigilo médico.

Estatísticas da previdência social, por exemplo, demonstram que os afastamentos relativos aos transtornos mentais ocupam a terceira maior causa (PIGNATI; MACIEL; RIGOTTO, 2013). Esses dados deveriam subsidiar posturas mais rígidas de controle das condições e organizações do trabalho em nível nacional por parte das instâncias políticas e governamentais com esse poder. Não é isso que se observa. As notificações se tornam um fim em si mesmas. Quais seriam as repercussões dessa prática para a produção de subjetividades dos trabalhadores? Como diagnosticar sem condenar o trabalhador com rótulos? Eis um dilema técnico e ético, pois um diagnóstico psiquiátrico pode significar uma condenação na trajetória dos sujeitos.

\section{Os efeitos dos diagnósticos}

Estudos têm identificado impactos dos diagnósticos na vida dos trabalhadores, nas relações sociais e na visão de si mesmos (BRANT; MINAYO-GOMEZ, 2008; MOULIN; MORAES, 2010). O diagnóstico de depressão, por exemplo, altera a noção de virilidade de muitos trabalhadores e suas relações familiares, 
uma manifestação singular do trabalhador como transtorno, ao invés de emancipar, pode aprisionar o trabalhador no discurso médico.

Essas ações podem significar a produção de uma subjetividade de adoecidos, em um jogo discursivo tão incapacitante quanto excludente. Trabalhadores diagnosticados como portadores de transtornos mentais têm sua trajetória moral e social alterada em função do veredito médico-sanitário. Para o trabalhador, essa prática pode significar a "certeza" de ser portador de um transtorno, munindo-o da informação necessária para iniciar uma nova trajetória em busca dos direitos e benefícios de um adoecido.

É preciso afirmar a complexidade da manifestação do sofrimento no âmbito laboral e a necessidade de cuidado e atenção no trato com essa dimensão da vida humana que, ao longo do tempo, vem sendo transformada em problemas médicos-psiquiátricos (CONRAD, 2007). Esse cuidado é fundamental, porque a construção de uma subjetividade reduzida à doença, em última instância, torna-se uma prática de eliminação dos "mais fracos psiquicamente", podendo transformar um conjunto de trabalhadores em "vidas indignas de serem vividas", conforme salienta Agamben (2007).

Afinal, a tendência de patologização dos trabalhadores - a transformação de trabalhadores em pessoas transtornadas - pode criar um mecanismo de exclusão do mercado de trabalho, além de repercussões na família, na comunidade e na vida social. Esses diagnósticos não estariam servindo para induzir formas de subjetivação reduzidas ao adoecimento? Em caso positivo, essa prática de subjetivação beiraria um perigo: ser um dispositivo de eliminação social de muitos trabalhadores. Uma espécie de política de morte - tanatopolítica - no sentido de Agamben, na medida em que busca dar esta forma à classe trabalhadora: adoecida mentalmente.

Como exemplo dessa vida indigna de ser vivida, Agamben (2007, p. 149) cita a eliminação de mais de sessenta mil doentes mentais na Alemanha do Terceiro Reich. Tratava-se de um programa eugênico, revestido de um discurso médico preventivista e humanitário, bem presente nas ações do nazismo. Por que Hitler executaria esse programa de eutanásia eugênica em nome da prevenção? "Não resta outra explicação além daquela segundo a qual, sob a aparência de um problema humanitário, no programa estivesse em questão o exercício, no horizonte da 
nova vocação biopolítica do estado nacional-socialista, do poder soberano de decidir sobre a vida nua" (AGAMBEN, 2007, p. 148). A vida indigna de ser vivida, portanto, não é um conceito ético e moral concernente aos indivíduos, mas político, ligado ao poder soberano e sua decisão sobre a vida matável. Ou seja, o Estado escolhe quem determinar como doente e que destino lhe dar.

Importante mencionar a ligação existente entre os psiquiatras brasileiros e as práticas psiquiátricas na Alemanha nazista, verificada entre os profissionais da Liga Brasileira de Higiene Mental, que inclusive publicou na íntegra a Lei assinada por Hitler sobre a esterilização dos doentes "transmissores de taras", nos Archivos Brasileiros de Hygiene Mental (CARVALHO, 1999).

Uma das primeiras leis do Terceiro Reich foi promulgada em 18 de outubro de 1933 e regulava a "proteção da saúde hereditária do povo alemão". Ela previa que a doença mental poderia impedir um casamento por ser indesejável para a comunidade nacional. Opera-se aí a prática política que busca formatar a existência de um povo (AGAMBEN, 2007).

Em que medida dispositivos como nexo causal e notificação compulsória não correm o risco de dar uma forma adoecida (mentalmente) à classe trabalhadora, quando buscam prioritariamente decifrar sintomas, enquadrando os trabalhadores em categorias psiquiátricas, agora articuladas com o cotidiano laboral? O que faz com que o Estado seja chamado para operar uma vigilância nas relações entre trabalho e saúde mental?

Para Agamben (2009), os dispositivos são práticas, saberes, regras, discursos que levam a processos de subjetivação. Enunciados, discursos e práticas de vigilância tradicional podem ser considerados dispositivos (normas técnicas, práticas e postulados científicos) de captura dos sujeitos trabalhadores, transformando-os em sujeitos transtornados. Um verdadeiro processo de construção social de sujeitos adoecidos se forma, facilitado por engrenagens no campo da saúde que focalizam os transtornos mentais e dele dependem para dar visibilidade à saúde mental na rede. Nesse sentido, as práticas de vigilância de agravos e de diagnóstico de trabalhadores não seriam instrumentos caça-doenças que produzem o fenômeno que tanto querem combater?

As práticas dos serviços médicos das empresas e alguns dispositivos de saúde do trabalhador - encaminhamentos médicos e psiquiátricos realizados pelos Cerest, levantamentos de problemas em saúde mental sob a ótica da epidemiologia 
tradicional, preocupações exclusivas com a evidência e diagnóstico clínico-

psiquiátrico para a notificação dos agravos - não revelariam o diagnóstico de uma epidemia e sim uma epidemia de diagnósticos? Ao identificar, diagnosticar e tratar a vigilância, produz-se o trabalhador mentalmente doente.

Nesses moldes, a saúde pública primeiro psiquiatriza os sujeitos para depois intervir. Ou seja, primeiro inventa-se a doença com base em jogos de verdades, depois busca-se identificar o seu "porta-dor" em locus de interesse. Um contrassenso se forma: a mesma saúde pública que faz a crítica da psiquiatrização a ela se submete e dela depende no campo da vigilância.

Não estamos negando a importância das notificações, mas consideramos ser inadequado utilizar o mesmo instrumental de vigilância de doenças infecciosas para as manifestações de sofrimento. Pois, conforme orientações do Ministério da Saúde (BRASIL, 2007), a notificação dos transtornos mentais dos trabalhadores só deve ser feita para os casos confirmados. É nesse sentido que a produção da "saúde mental" depende de um contingente de "doentes confirmados".

Essa ideia dos "casos confirmados" acaba valorizando as patologias, em detrimento de toda a variedade das manifestações do sofrimento. O problema é que os conceitos de transtorno e doença mental obscurecem "o fato cotidiano de que a vida, para a maioria das pessoas, é uma luta contínua, não pela sobrevivência biológica, mas 'por um lugar ao sol', 'paz de espírito', ou algum outro significado ou valor" (SZASZ, 1977, p. 28-29). A ideia de doença mental funcionaria como um mito moderno, similar à função do mito na religião, para disfarçar os conflitos nas relações humanas, operando uma redução na qual toda a complexidade dos fenômenos sociais passa a ser lida como doença individualizada. Para Szasz (1977), a doença mental é uma questão de eventos sociopsicológicos e deveria ser categoria revista e retirada do rol das patologias e passar a ser entendida "como expressão do esforço do homem com o problema de como ele deveria viver" (SZASZ, 1977, p. 28). Ou seja, o ser humano teria um problema existencial, e sua transformação em psicopatologia compõe um amplo discurso social que produz sujeitos adoecidos.

Da mesma forma como a Idade Média produzia as feiticeiras por um processo social de atribuição de um papel ao outro, existe um processo contemporâneo de fabricação do doente mental. "Cada vez que psiquiatras criam uma nova regra de saúde mental, criam uma nova classe de indivíduos mentalmente 
1282 doentes" (SZASZ, 1978, p. 27). Essa é uma armadilha para o campo da saúde, que, no afã de intervir no processo saúde-doença, patologiza trabalhadores por meio de dispositivos sanitários, tornando-se um mecanismo político para "dar forma à vida de um povo" (AGAMBEN, 2007, p. 155). Essa patologização do trabalhador funcionaria como uma ideologia que acoberta as contradições dos processos de trabalho.

\section{A profanação como alternativa possível}

Como avançar no âmbito das práticas sem incorrer no fortalecimento de processos de patologização? Como abordar as demandas que chegam à rede de saúde $\mathrm{e}$ de que modo entender esses fenômenos dando suporte para ações coletivas de transformação das condiçõos laborais?

A questão central a considerar é que a saída para esses dilemas passa pela profanação dos dispositivos de patologização (AGAMBEN, 2009), instaurando um processo dessacralizador dessa engrenagem clínica e epidemiológica como únicos critérios válidos para desencadear açōes em saúde do trabalhador.

É crucial que outros meios e estratégias rompam com essas ênfases. Para isso, destacamos elementos que podem auxiliar nessa direção.

\section{A busca pela superação do modelo mental}

O uso da expressão saúde "mental", frequentemente, remete às situações do "mundo interior". Aliás, o conceito de mente como a substância imaterial dentro do Ser esteve presente na história do pensamento ocidental (RORTY, 1994).

Foi no século XVII que emergiu de modo inédito a ideia de uma separação entre eventos de uma vida interior e eventos de um mundo externo, construindo assim uma dada esfera mental. Descartes apresentou a noção de organismo composto de res cogitans e res extensa, e, assim, compreendeu-se o mental como aquilo que contrasta em natureza com o corporal. A mente estaria em contraste com o meramente físico (o corpo, a matéria). "A novidade foi a noção de um único espaço interno, onde sensações corpóreas e perceptivas, verdades matemáticas, regras morais, a ideia de Deus, disposições depressivas e todo o resto do que agora chamamos 'mental' eram objetos de certa observação" (RORTY, 1994, p. 62).

Uma diversidade de sentidos sobre a "mente" se desenvolveu: I) mente como representação da essência ou do conhecimento das essências; II) como substância 
imaterial do homem - sua alma, o mundo dos afetos e emoções; III) como aparelho psíquico formado por um inconsciente universal e a-histórico; IV) como uma máquina processadora de informações, criadora de representações sobre o mundo externo.

Esse último aspecto é muito presente atualmente, quando emerge a noção de sujeito neurônico ou cerebral. Aqui, a ideia é que a mente funcionaria como um processador de informações por meio das conexões neuronais e outros processos químicos. No bojo dessa tradição, tem crescido a ideia de que toda patologia mental envolve o cérebro e a neuroquímica - neurônios, sinapses, neurotransmissores, enzimas (ROSE, 2003).

Isso tem gerado as sociedades psicofarmacológicas, nas quais as subjetividades são controladas pelo uso de drogas. Sintomas passam a ser tratados por medicamentos. Cada vez mais essa visão é presente entre médicos, psiquiatras e demais categorias profissionais, espalhando-se em espaços privados, em especial nas relações familiares.

Essa ênfase emergiu entre as décadas de 1950 e 60, associada a um lucro exorbitante da indústria farmacêutica. Se no século XXI os hospícios viraram um "bom negócio", no século XX foi a vez das psicoterapias, e atualmente ganha relevo a psicofarmacologia. Pode-se falar não apenas em biopolítica, mas em bioeconomia (ROSE, 2003). Salientamos que a noção já popularizada de problemas "mentais" é perigosa, imprecisa e limitada para designar os fenômenos relativos à subjetividade-trabalho.

A busca da superação do modelo mental é crucial para a vigilância passar das práticas clínicas voltadas aos indivíduos em direção às ações coletivas. Até porque a noção de mental - esfera individual e uma dimensão distinta do corpo físico - pode levar à dicotomização, subsidiando açôes segmentadas sobre riscos e impactos no corpo dos trabalhadores, deixando na invisibilidade aspectos que afetam sua subjetividade.

\section{Das doenças às manifestações do sofrimento}

Para Rotelli (1990, apud TORRE; AMARANTE, 2001), em lugar da doença mental deve-se falar em existência-sofrimento do sujeito em sua relação com o corpo social. Pensar na categoria sofrimento pode abrir novas possibilidades de ações de intervenção, considerando os sujeitos e seus processos de trabalho, 
acolhendo suas queixas a fim de gerar processos de pesquisa-ação sobre a organização de trabalho por território, setor produtivo, ramo de atividades. Nessa perspectiva, o sofrimento do trabalhador procede das múltiplas relações dos sujeitos no contexto laboral, que se apresenta como uma ameaça à sua existência e não constitui uma doença segundo o modelo biomédico.

Segundo Freud (1920), o sofrimento é um estado de expectativa frente ao perigo e preparação para ele, ainda que seja um perigo desconhecido (angústia); medo, quando ele é conhecido; ou susto, quando o sujeito topa com um perigo sem estar preparado para enfrentá-lo. O sofrimento se configura como uma reação do sujeito, uma manifestação da insistência em viver em um ambiente que, na maioria das vezes, não lhe é favorável.

Nessa perspectiva, a manifestação do sofrimento pressupõe a existência de um registro mnemônico e um código linguístico que permite identificar, nomear e comunicar determinadas percepções avaliadas como ameaça. Na preparação para enfrentá-las, é possível encontrar a dimensão do sujeito enquanto subjectus, a sua submissão a determinados discursos. É exatamente a inserção num discurso que permite a representação de um acontecimento como perigoso ou não, portanto, capaz ou não de desencadear sofrimento. O risco no ambiente laboral pode ser ou não percebido pelo sujeito como ameaça. A situação de risco é uma mesclagem de experiência e memória, jamais um fator. Portanto, a manifestação do sofrimento constitui uma positividade, um alerta sinalizando a necessidade de transformações no trabalho (BRANT, 2004).

Identificar o sofrimento expresso nas relações de trabalho é fundamental para a Visat, porque o reconhecimento da origem dessa manifestação impulsiona à luta política e não à autocomiseração. Existe uma produção de múltiplas ameaças nos processos de trabalho. Como esse sofrimento tem essa origem social, a maneira de enfrentá-lo precisa também ser social e não médica (RENAULT, 2008). Por isso, a mobilização do conjunto de atores que implementam as práticas de Visat é central para a intervenção nas situações geradoras. Isso implica em participação ativa dos trabalhadores nas lutas para o enfrentamento dos determinantes de seu sofrimento.

Se o sofrimento implica em uma tentativa de diminuição dos trabalhadores (não reconhecimento, baixos salários, estratégias de culpabilização, humilhações, pouca margem de escolha e participação, regras inflexíveis e injustas, entre 
outros), o fortalecimento dos próprios trabalhadores em sua condição de sujeitos autônomos para protagonizarem transformações no seu cotidiano é um imperativo. Daí a importância da mobilização de representação de trabalhadores para fortalecer sua resistência perante situações enfrentadas em cada ramo econômico e processo de trabalho específico.

\section{Do diagnóstico clínico à compreensão conjunta do sofrimento}

Consequentemente, novas formas de diagnóstico precisam ser desenvolvidas para confrontar práticas instituídas na saúde pública, nas perícias do INSS e na justiça do trabalho, ainda calcadas nos modelos positivistas, matemáticos e biomédicos.

A matematização operada pelo saber e prática epidemiológicos funda ações de catalogação de problemas em saúde mental. Essas são importantes, porém deixam à margem o sofrimento, posto que é categoria impassível à quantificação. Não podemos negar que a criação de indicadores de saúde mental relacionada ao trabalho é uma importante ação para dimensionar os problemas da classe trabalhadora. Uma ação de vigilância epidemiológica em saúde do trabalhador.

A nosso ver, a manifestação do sofrimento deve ser o foco. Assim, a questão não é diagnosticar e classificar pessoas pelo olhar técnico e médico, mas a necessária escuta do sofrimento pelas equipes de saúde, tendo como referência o conjunto de situações e contextos que forjam os processos de subjetivação.

Nesse sentido, é preciso avançar em termos de superação do modelo positivista para elaboração e emissão de laudos e pareceres de instituições e profissionais da saúde para garantir acesso a direitos do trabalho, operados pelo judiciário, pelo INSS, entre outros. Da mesma forma, talvez seja necessário assumir outra lógica como potência para ressaltar a subjetividade e o sofrimento como categorias centrais para ações inovadoras no campo da saúde pública.

Para isso se faz necessário no SUS fazer avançar as práticas integradas de Visat a partir de uma recusa sistemática à dicotomia cartesiana entre res cogitans e res extensas, que sustenta paradigmas de ação da vigilância voltados apenas para aspectos materiais, palpáveis.

Outra questão está na valorização das experiências dos sujeitos na resistência às ameaças no trabalho e em suas estratégias de manutenção da vida e da saúde, como forma de construir possibilidades de ações em Visat que fortalecem esses aspectos. Isso implica em considerar os trabalhadores, não como agentes passivos 
aos impactos da organização do trabalho e carentes da proteção da vigilância, mas como sujeitos ativos que reagem, resistem, criam estratégias para transformar situações do seu cotidiano de trabalho. Valorizar esse potencial transformador ativo entre os trabalhadores é fundamental, porque saúde é também a capacidade de um grupo social controlar e dirigir seus processos vitais (NORIEGA, 1993).

\section{Do dado epidemiológico às múltiplas informações}

Não se podem desprezar os limites epistemológicos dessa busca pelo nexo causal e por informações seguras e objetivas sobre transtornos mentais e trabalho. Essas ações de caráter epidemiológico e biomédico (na medida em que transformam sofrimento em patologia), procuram associar um conjunto de evidências relativas a sintomas clínicos e ao contexto ocupacional-ambiental, considerando casos individuais ou um conjunto de populações (PORTO; FINAMORE, 2012).

Essa lógica de "informação para a ação" reflete uma racionalidade instrumental baseada na pressuposição de previsibilidade e estabilidade dos fenômenos. Essa visão subsidia a lógica de que, uma vez detectados dados e informações sobre o fenômeno - as "descobertas", desvelamentos de fatos e verdades das coisas -, se deslancham ações de controle e intervenção.

No caso da saúde mental, não estamos lidando com uma dada estabilidade de fenômenos da mente e suas relações com o trabalho, mas da esfera das relações entre a subjetividade e o processo de trabalho, em seus aspectos técnicos, sociais, culturais e econômicos. A questão se torna complexa demais justamente aí. Os fenômenos da saúde mental dos trabalhadores se dão em e nas relações.

Outras abordagens, como a epidemiologia popular, inicialmente proposta por Phil Brown (1987), e a epidemiologia social, conforme Jaime Breilh (2003), questionam o modelo epidemiológico clássico. Apontando seu reducionismo e chamando a atenção para a necessidade de novas formas de produção de informações e monitoramento de situação de saúde, ressaltam a participação da população para a expressão de seus sofrimentos.

Como avançar nessa direção, em mecanismos de participação da população para a produção de informação para a vigilância em saúde mental do trabalhador? Isso é crucial, principalmente porque, na abordagem clássica, a produção de informação é uma ação eminentemente técnica e não social. Conforme Albuquerque (1978, p. 38): "É interessante notar que as primeiras noçôes de 
epidemiologia avant la lettre coincidem com as ideias de degenerescência moral e social - coincidência de que é exemplo eloquente a ambiguidade médico-moral de termos como 'contágio', 'contaminação', etc'.

Abordagens para além da epidemiologia clássica podem dar maior visibilidade às preocupações e sofrimentos das comunidades, incluindo os trabalhadores, e levar à criação de estratégias de emancipação e protagonismo dos sujeitos na transformação da realidade e condição de saúde.

É preciso superar a ênfase nos indicadores quantitativos expressos em taxas, índices e coeficientes (HENNINGTON; FREITAS, 2009, p. 120). Assim, utilizar indicadores sociais, abordagens qualitativas e estratégias de integração da população trabalhadora na produção de dados, para a melhor compreensão das demandas, pode ser fator importante.

\section{Da clínica às intervenções heterogêneas}

Além disso, é preciso abrir um leque de atuações em função das situações presentes nas dinâmicas territoriais dos Cerests. Existe uma heterogeneidade e multiplicidade de ações possíveis.

Compreendemos a vigilância em saúde mental do trabalhador como um conjunto de ações que incidem sobre os sofrimentos dos trabalhadores em níveis diferenciados. Essas ações abrangem o atendimento aos casos individuais mais graves, a intervenção na organização do trabalho, integrando os aspectos psicossociais aos riscos ocupacionais, aproximaçôes e articulações com organizações de geração de renda e inserção no mercado de trabalho de pessoas em sofrimento, a fiscalização dos produtos químicos perigosos (agrotóxicos etc.), entre outros.

A missão dos Cerest é difundir ações na rede de saúde, e não funcionar como referência para tratamentos de trabalhadores supostamente adoecidos ou mesmo instâncias de orientação trabalhista e previdenciária. Para cumprir seu objetivo de ser um centro de articulação de ações em saúde do trabalhador, uma das primeiras ações é identificar possíveis instâncias parceiras na rede de saúde local e em outros órgãos do Estado. Outra ação fundamental é identificar atores sociais e entidades representativas da comunidade e trabalhadores presentes no território para criar parcerias/ações conjuntas e deslanchar processos de vigilância partindo das principais fontes de sofrimento dos trabalhadores. 
Cada setor de trabalho e suas representaçōes de categoria deve desempenhar uma luta de identificação de situações em seus ramos produtivos, contando com as parcerias entre os Cerest, para compreender fontes e níveis do sofrimento e propor mudanças na organização do trabalho.

\section{Considerações finais}

É fundamental criar estratégias no interior das práticas em saúde que rompam com a história marcada por dispositivos de patologização, desenvolvendo novos embasamentos para ir além da coleta e registro dos agravos à saúde mental e de práticas clínicas. $\mathrm{O}$ modo como a temática da saúde mental, sofrimento e trabalho vem sendo tratada no SUS, no âmbito da Renast, demonstra os limites desses enfoques da Visat.

Para avançar, faz-se necessário enfrentar o desafio de compreender os fenômenos em saúde mental e de lidar com situações complexas, dadas as múltiplas manifestações do sofrimento relacionado ao trabalho e suas diferenças e níveis. Isso implica problematizar os dilemas para a produção de informação e as práticas de notificação no Sinan, que enfatizam apenas a dimensão quantitativa dos fenômenos e são voltadas para a detecção, o diagnóstico e a notificação de transtornos.

O desafio para a Renast é construir outras possibilidades de produção de informação para embasar ações da vigilância, indo além do enfoque centrado nos diagnósticos e nos transtornos mentais e do comportamento, e impulsionar açōes de intervenção perante as manifestações de sofrimento.

Passos podem ser dados à medida que investimentos sejam feitos visando à passagem do modelo mental à produção das subjetividades, das patologias às manifestações de sofrimento, do dado epidemiológico às múltiplas informações, do diagnóstico clínico ao social, da escuta individual à grupal/coletiva, da clínica à heterogeneidade das intervençôes. Nesse sentido, a Visat se fortaleceria como estratégia potencializadora da emancipação dos trabalhadores. ${ }^{1}$

\section{Referências}

AGAMBEN, G. O que é o contemporâneo? E outros ensaios. Chapecó: Argos, 2009. 92p. Homo Sacer I - O poder soberano e a vida nua. Belo Horizonte: Editora UFMG, 2007. 207p. 
ALBUQUERQUE, J. A. G. Metáforas da desordem: O contexto social da doença mental.

Rio de Janeiro: Paz e Terra, 1978. 119p.

ANSPACH, R. R. Preface. In: MCGANN, P. J.; HUTSON, D. J. Sociology of diagnosis. Bingley: Emerald, 2011. p. xiii-xxvii.

BRANT, L. C.; MINAYO-GOMEZ, C. Da tristeza à depressão: a transformação de um mal-estar em adoecimento no trabalho. Interface, Botucatu, v. 12, n. 26, p. 667-676, 2008. BRANT, L. C. O processo de transformação do sofrimento em adoecimento no âmbito da gestão do trabalho. 2004. 92 p. Tese. (Doutorado em saúde pública) - Escola Nacional de Saúde Pública, Fundação Oswaldo Cruz, Rio de Janeiro, 2004.

BRASIL. Ministério da Saúde. Portaria no 1.823, de 23 de agosto de 2012. Institui a Política Nacional de Saúde do Trabalhador e da Trabalhadora. Diário Oficial [da] República Federativa do Brasil, Brasília, DF, p. 46-51, 24 ago. 2012. Seção I.

. Portaria $\mathrm{n}^{\circ} 1.339 / \mathrm{GM}$, de 18 de novembro de 1999. Institui a lista de doenças relacionadas ao trabalho. Diário Oficial [da] República Federativa do Brasil, Brasília, DF, p. 21, 19 nov. 1999. Seção 1.

. Doenças Relacionadas ao Trabalho: Manual de Procedimentos para os Serviços de Saúde. Série A. Normas e Manuais Técnicos. Brasília: Ministério da Saúde, 2001.

. Portaria GM no 104, de 25 de Janeiro de 2011. Define as terminologias adotadas em legislação nacional, conforme o disposto no Regulamento Sanitário Internacional 2005 (RSI 2005). Diário Oficial [da] República Federativa do Brasil, Brasília, DF, p. 37-38, 26 jan. 2011. Seção 1 .

Sistema de Informação de Agravos de Notificação. 2. edição. Série A. Normas e Manuais Técnicos. Brasília: Editora MS, 2007. 68p.

BREILH, J. De la vigilancia convencional al monitoreo participativo. Ciência \& Saúde Coletiva, Rio de Janeiro, v. 8, n. 4, p. 937-951, 2003.

BROWN, P. Popular Epidemiology: Community Response to Toxic Waste-Induced Disease in Woburn, Massachusetts. Science, Technology, \& Human Values, London, v. 12, n. 3/4, p. 78-85, 1987.

CARVAlHO, A. M. T. de. Trabalho e Higiene Mental: processo de produção discursiva do campo no Brasil. História, Ciências, Saúde-Manguinhos, Rio de Janeiro, v. 6, n. 1, p. 133-156, 1999.

CONRAD, P. The medicalization of society: on the transformation of human conditions into treatable disorders. Baltimore: Johns Hopkins Press, 2007. 224p.

DECLICH, S.; CARTER, A. O. Public health surveillance: historical origins, methods and evaluation. Bulletin of the World Health Organization, Geneva, v. 72, n. 2, p. 285-304, 1994. DELEUZE, G. Post-scriptum sobre as sociedades de controle. Tradução de Pal Pélbart. In: . Conversaçôes (1972-1990). Rio de Janeiro: Ed. 34, 1992. p. 219-226. 
FABREGA, H. Jr. Cultural and historical foundations on psychiatric diagnosis. In MEZZICH, J. E.; KLEINMAN, A. M. D. (Org.). Culture and psychiatric diagnosis: A DSM- IV perspective. Washington: American Psychiatric Press, 1996. p. 3-14.

FOUCAULT, M. Vigiar e punir. Petrópolis: Vozes, 1987. 288p. . O nascimento da clínica. Rio de Janeiro: Forense, 1998.

FREUD S. Além do princípio do prazer. In: . Obras completas, v. XVIII, Rio de Janeiro: Imago, [1920] 1997.

GORZ, A. O imaterial: Conhecimento, Valor e Capital. São Paulo: Annablume; 2005. 107p. GUATTARI, F. As três ecologias. Campinas: Papirus, 2000. 56p. . Caosmose - Um novo paradigma estético. Editora 34: São Paulo, 1992. 203p.

HENNINGTON, E. A.; FREITAS, M. B. Informação para ação em saúde do trabalhador. In: MINAYO-GOMEZ, C.; VASCONCELLOS, L. C. F. (Org.). Controle social na saúde do trabalhador. Rio de Janeiro: EAD/Ensp, 2009. p. 117-130.

JARDIM, S. R.; RAMOS, A.; GLINA, D. M. R. Diagnóstico e nexo com trabalho. In: GLINA, D. M. R.; ROCHA, L. E. Saúde Mental no Trabalho: da teoria à prática. São Paulo: Roca, 2010. p. 49-80.

LAZZARATO, M.; NEGRI, A. Trabalho imaterial. Formas de vida e produção de subjetividade. Rio de Janeiro: DP\&A, 2001. 112p.

LEĀO, L. H. C. Nas trilhas das cadeias produtivas: subsídios para uma política integradora de vigilância em saúde. 2011. 191 p. Dissertação. (Mestrado em saúde pública) - Escola Nacional de Saúde Pública, Fundação Oswaldo Cruz, Rio de Janeiro, 2011.

MOUlin, M. G. B.; MORAES, A. B. T. Vamos fazer poeira! Fontes e expressões da pressão no trabalho do setor de rochas ornamentais no Espírito Santo. Revista Brasileira de Saúde Ocupacional, São Paulo, v. 35, n. 122, p. 192-200, 2010.

NORIEGA, M. Organización laboral, exigencias y enfermedad. In: LAURELL, A. C. (Org.). Para la Investigación de La Salud de los Trabajadores. Washington: Organización Panamericana de la Salud, 1993. p. 167-188.

PIGNATI, W. A.; MACIEL, R. H. M. O.; RIGOTTO, R. M. Saúde do trabalhador. In: ROUQUAYROL, M. Z.; GURGEL, M. (Org.). Epidemiologia e Saúde. 7a Edição. Rio de Janeiro: Medbook, 2013. p. 355- 381.

PORTO, M. F.; FINAMORE, R. Riscos, saúde e justiça ambiental: o protagonismo das populações atingidas na produção de conhecimento. Ciência \& Saúde Coletiva, Rio de Janeiro, v. 17, n. 6, pp. 1493-1501, 2012. 
RENAULT, E. Souffrances Sociales: Philosophie, psychologie et politique. Paris : Editions la Découverte, 2008. 405 p.

- Du fordisme au post-fordisme: Dépassement ou retour de l'aliénation? Actuel Marx, Paris, v. 1, n. 39, p. 89-105, 2006.

RORTY, R. A filosofia e o espelho da natureza. Rio de Janeiro: Relume-Dumará, 1994. 310p.

ROSE, N. Neurochemical selves. Society, New York, v. 41, n. 1, p. 46-59, 2003.

SABROZA, P. Vigilância em Saúde. s/d. Disponível em <http://www.abrasco.org.br/ grupos/arquivos/20060718160725.pdf> Acesso em 06/01/2013.

SZASZ, T. S. A fabricação da loucura: Um estudo comparativo entre a Inquisição e o Movimento de Saúde Mental. Tradução de Dante Moreira Leite. Rio de Janeiro: Zahar Editores, 1978.

. Ideologia e doença mental: Ensaios sobre a desumanização psiquiátrica do homem.

Rio de Janeiro: Zahar Editores, 1977.

TORRE, E. H. G.; AMARANTE, P. Protagonismo e subjetividade: a construção coletiva no campo da saúde mental. Ciência \& Saúde Coletiva, Rio de Janeiro, v. 6, n. 1, p. 73-85, 2001.

VERTHEIN, M. A. R.; MINAYO-GOMEZ, C. Movimentos de assepsia social: a doença do trabalho fora de alcance. In: MINAYO-GOMEZ, C; MACHADO, J. H. M.; PENA, P. G. L. Saúde do trabalhador na sociedade brasileira contemporânea. Rio de Janeiro: Fiocruz, 2011. p. 273-296.

\section{Nota}

${ }^{1}$ L.H.C Leão participou da concepção da pesquisa, análise e interpretação dos dados e redação do artigo. L. C. Brant realizou a revisão crítica do conteúdo intelectual do artigo e aprovou a versão a ser publicada. 
Suffering manifestations: dilemmas and challenges for worker's health surveillance This paper addresses complex and challenging relations suffering's manifestations of workers and health surveillance practices. It is a theoretical essay whose objective is to perform a critical analysis about challenges and dilemmas related to mental health integration in worker's health surveillance in the Brazilian health system. We realize that some practices from public health services has pathologized workers and, therefore, based on theoretical premises from authors like Agamben, Guattari, Szasz e Rorty, we discuss conceptual and practice dilemmas, technical and ethical dilemmas of mental disorders related to word diagnosis. We also highlight risks and dangers from hegemonic tendency focused on epidemiological and biomedical approach to deal with worker's suffering manifestations. Finally, we point out alternatives to the development of strategies to break with pathologizing devices of worker's sufferings.

> Key words: mental health; suffering; subjectivity; surveillance, medicalization. 